\title{
Acute and repetitive fronto-cerebellar tDCS stimulation improves mood in non-depressed participants
}

\author{
Simon Newstead ${ }^{1} \cdot$ Hayley Young ${ }^{1} \cdot$ David Benton $^{1} \cdot$ Gabriela Jiga-Boy $^{1,4}$. \\ Maria L. Andrade Sienz ${ }^{2}$ R. M. Clement ${ }^{3,4} \cdot$ Frédéric Boy ${ }^{4,5}$
}

Received: 31 May 2017 / Accepted: 16 October 2017 / Published online: 2 November 2017

(c) The Author(s) 2017. This article is an open access publication

\begin{abstract}
Transcranial direct current stimulation (tDCS) is a non-invasive form of brain stimulation, which allows for selective inhibition or excitation of neural structures. It has demonstrated some efficacy in the treatment of mood disorders. However, these studies have predominately focused on stimulation of the prefrontal cortex (PFC). The cerebellum has an increasingly recognized role in emotional control, affective state, and some psychopathologies. As such, tDCS research into mood modulation needs to expand beyond conventional PFC-focused paradigms. Using a contralateral stimulation electrode placement [anodal left dorsolateral(dl) PFC, cathodal right cerebellum], and a single-blind, repeated-measures design, we initially assessed changes in the mood of healthy participants in response to acute stimulation $(n=44)$ and three repeated stimulations delivered
\end{abstract}

Electronic supplementary material The online version of this article (doi:10.1007/s00221-017-5109-y) contains supplementary material, which is available to authorized users.

Simon Newstead

s.newstead.882183@swansea.ac.uk

$\triangle$ Frédéric Boy

f.a.boy@swansea.ac.uk

1 Department of Psychology, Swansea University, Swansea, UK

2 College of Human and Health Sciences, Swansea University, Swansea, UK

3 School of Management, Swansea University, Swansea, UK

4 CHEMRI, Center for Health and Environmental Management Research and Innovation, School of Management, Swansea University, Swansea, UK

5 UCL Department of Medical Physics and Biomedical Engineering, Malet Place Engineering Building, Gower Street, London, UK second-daily $(n=21)$. In a second experiment, we separately investigated the influence of reversed polarity upon these same measures, in response to acute stimulation $(n=23)$ and repeated stimulation $(n=11)$. We observed a systematic elevation of mood in both active conditions following single and repeated tDCS, the latter of which displayed a progressive elevation of mood from baseline. No mood change was noted in response to either single or repeated stimulation in the sham condition. Frontocerebellar tDCS stimulation advantageously influences mood in healthy participants, with an accumulative and potentiated effect following successive stimulations. The possibility that frontocerebellar stimulation may provide a novel therapeutic adjunctive or pre-emptive intervention in stress-related disorders and mood-related psychopathologies should be considered.

Keywords tDCS $\cdot \mathrm{dlPFC} \cdot$ Cerebellum $\cdot$ Mood $\cdot$ Healthy participants

\section{Introduction}

Prolonged levels of stress can precipitate the development of anxio-depressive symptomology (Charles et al. 2013). With depression currently affecting some 350 million individuals worldwide (WHO 2016), the estimated financial burden of these conditions up until 2030 is more than $£ 100$ billion (Chisholm et al. 2016). As such, there is a crucial need for developing cost-effective, stand-alone or adjunctive treatments. Advances in the fields of brain stimulation herald new therapeutic avenues, with fundamental and clinical research providing some evidence as to the efficacy of two forms of non-invasive brain stimulation in the treatment of mood disorders: repetitive transcranial magnetic stimulation (rTMS) (Loo and Mitchell 2005; George et al. 2000) and 
transcranial direct current stimulation (Boggio et al. 2008; Brunoni et al. 2013; Kalu et al. 2012; Loo et al. 2012; Minichino et al. 2014; Nitsche et al. 2009). However, as recent meta-analyses highlights (Lefaucheur et al. 2017) there is some contention regarding the efficacy of tDCS for the modulation of depressive symptomology. More specifically, receptiveness to conventional pharmacological intervention appears to be a prerequisite for improvements resulting from tDCS (Brunoni et al. 2016; Lefaucheur et al. 2017) (See online resources, Sect. 1 for a table of prior mood modulation protocol).

One potential avenue would be to investigate mood modulation in healthy participants, in the hope that tDCS could provide a preemptive therapeutic intervention. To date, whether examining neuropsychiatric disorders such as depression, or healthy participants, research into the modulation of mood states has predominately focused on the role played by the PFC (e.g. Davidson 2002; Greicius et al. 2007a; Holzschneider and Mulert 2011; Mayberg et al. 1997; Seminowicz et al. 2004; Telzer et al. 2008). The basis for neuromodulation with regard to depression is premised on observations of hypoactivity of the left dlPFC, as indicated by reduced glucose metabolism or blood flow (Baxter et al. 1989; Blumberger et al. 2012; Brunoni et al. 2012a; Fitzgerald et al. 2006), and the theory that it is possible to ameliorate depressive symptoms by addressing this dysfunctional imbalance between the hemispheres via anodal stimulation of the left dIPFC.

As neuroimaging studies (NIRS) have demonstrated that tDCS can produce electrode dependent changes in surface BOLD response (Merzagora et al. 2010), and normalisation of left dlPFC hypoactivity has been observed following successful antidepressant treatment (Baxter et al. 1989; Fales et al. 2008; Kennedy et al. 2001), this logic is not without merit. However, not unsurprisingly given the aetiology of MDD, observations regarding lateralised hypo-/hyper activity are inconstant and not confined to the dlPFC (for example, Brooks et al. 2009; Drevets et al. 2002; Greicius et al. 2007a).

When considering mood modulation in healthy participants, it is important to acknowledge the areas where previous studies into depression have documented success or failure in the modulation of neurologic activity with tDCS. However, given the differences observed between healthy controls and sufferers of depression, replication of results obtained in depression studies cannot necessarily be anticipated. Numerous studies highlight changes in functional connectivity and grey and white matter density, of cortical and subcortical structures (Amico et al. 2011; Chang et al. 2011; Davis 2004; Lacerda et al. 2004; Martinot et al. 2011; Taylor et al. 2004), which would influence current density and flow through prefrontal structures (Shahid et al. 2013).
As a recent review highlights (Remue et al. 2016), prefrontal tDCS does not appear to offer mood improvements in healthy participants following single stimulation. Although some success has been achieved with repetitive stimulation using the F3 anode/F4 cathode electrode placement (Austin et al. 2016), it is worth considering that prefrontal orientated electrode positioning, whilst relatively focal, may not produce the optimal montage for mood modulation. Given that inter-electrode distance influences the degree of shunting and the amount of current which enters the brain (Bikson et al. 2010), it may even be considered somewhat restrictive in terms of the modulation of brain regions associated with limbic and affective process. Thus, whilst a number of tDCS paradigms with clearly established safety protocols have been published (e.g. Palm et al. 2012; Ferrucci et al. 2009), an optimal stimulation paradigm remains to be defined. Consequently, there is a need to expand beyond the established frontal-orientated montages.

One brain region with an increasingly commonly recognized role in cognition and emotion is the cerebellum (Adamaszek et al. 2017; Hone-Blanchet et al. 2015; Strata 2015; Stoodley 2012; Stoodley and Schmahmann 2010). Animal studies historically implicate it as an important component in higher brain functions and affective behaviours (Berman et al. 1974; Berrnan 1997). Despite only comprising $10 \%$ of the brain's volume, the cerebellum contains approximately $80 \%$ of its neurones (Herculano-Houzel 2009). It is, therefore, not surprising that investigations into the effects of modulation of cerebellar activity, via both tDCS (as highlighted by Ferrucci et al. 2016; Grimaldi et al. 2016) and rTMS (e.g. Gironell et al. 2002; Popa et al. 2013; Schutter and van Honk 2009; Zunhammer et al. 2011) have gained momentum over the last decade or so. Moreover, it is increasingly recognized that differences in cerebellar morphology and activation (Peng et al. 2011; Daskalakis et al. 2008; Konarski et al. 2005) play an important role in the onset and maintenance of mood disorders (Perciavalle et al. 2013; Turner et al. 2007; Schutter and van Honk 2005; Schmahmann 2004; Schutter et al. 2003).

The cerebellum possesses hemispherical laterality and has demonstrated asymmetry in functional coupling between its two hemispheres and their contralateral cerebrum $(\mathrm{Hu}$ et al. 2008; Wang et al. 2013). When not externally stimulated, the cerebellum exerts an overall inhibitory tone over the frontal cerebral cortex (cerebello-brain inhibition-CBI) via dentate-thalamo-cortical connections (Middleton and Strick 2001). It has been hypothesised that cerebellar tDCS produces behavioural and neurophysiological changes via excitation or suppression of its GABAergic Purkinje cell activity (Galea et al. 2009). A reduction of CBI, with subsequent potentiated disinhibition of the cerebral cortex, has already been reported in response to cathodal stimulation 
of the right cerebellum (Block and Celnik 2013; Pope and Miall 2012; Galea et al. 2009).

To date, a number of studies have examined frontocerebellar tDCS for a variety of clinical applications, such as essential tremor control (Gironell et al. 2014), obsessive-compulsive disorder (Bation et al. 2016), bipolar disorder (Bersani et al. 2015; Minichino et al. 2014), and hand dystonia (Bradnam et al. 2015). However, we believe we are the first to investigate the influence of a contralateral frontocerebellar stimulation electrode placement upon state, self-evaluated mood of healthy participants in response to acute and repetitive stimulation.

Prior mood modulation research has predominantly focused on extended periods ( $\geq 20 \mathrm{~min}$ ) of daily stimulation for approximately 2 weeks or (Bueno et al. 2011; Ferrucci et al. 2009; Palm et al. 2012) (See also online resources, Sect. 1). Recent work, however, has demonstrated the potential for shorter (12 min) bilateral stimulations of the dIPFC to positively modulate mood in healthy individuals (Austin et al. 2016), which was incorporated into our study design.

In the present study, we expand upon established prefrontal focused stimulation protocol situating the anode over the left dIPFC and the cathode over the right hemisphere of the cerebellum. We hypothesised that contralateral frontocerebellar stimulation would produce a measurable change in mood. To examine the polarity-dependent effects of stimulation upon mood we then conducted a second experiment in which the frontocerebellar montage was reversed, such that the left dIPFC received cathodal stimulation and the right cerebellum received anodal stimulation.

\section{Materials and methods}

\section{Design}

We employed a single-blind, repeated-measures design, in which participants were blind, and administrators of the stimulation utilised a set of codes to initiate a sham or active stimulation. Participants either signed up to complete a single stimulation or 3-stimulation experiment and were randomly allocated to the different conditions by use of a random sequence generator (random.org 2017). In both experiments, all participants completed session 1 (Fig. 1a), whilst only those who had previously signed up for the 3 -stimulation experiment proceeded to complete sessions 2 and 3. The three sessions were delivered over a 5-day period, on days 1, 3 and 5 (Fig. 1b). Sessions 1 and 3 were run in the same manner with consistent timings between elements, with the exception that the BAI and BDI-II were only administered in session 1 . Session 2 consisted of stimulation only.

\section{Procedure and materials}

Session 1 consisted of the completion of questionnaires related to demographic information. This was followed by completion of the BAI and BDI-II. Participants then undertook a Flanker Task test of focused attention and response inhibition (further detail relating to the procedure and parameters of the Flanker Task are included in online resources, Sect. 6). They were then asked to complete a visual analogue scale based on the dimensions of the bipolar Profile of Mood. This was followed by application of a set of $5 \mathrm{~cm} \times 5 \mathrm{~cm}$ rubber/graphite electrodes, closely fitted in specially designed saline-soaked $(0.9 \% \mathrm{w} / \mathrm{v} \mathrm{NaCl})$ sponge pockets, and administration of either Active or Sham

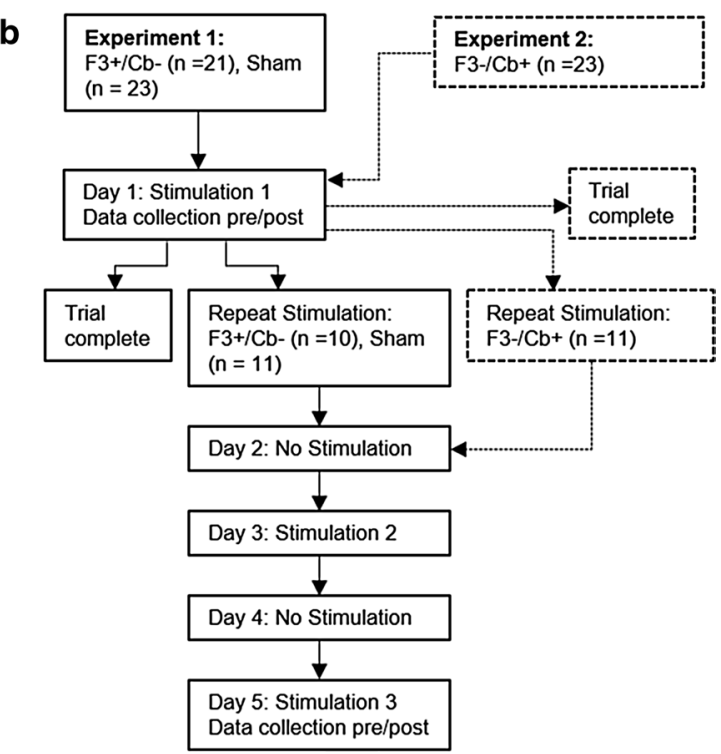

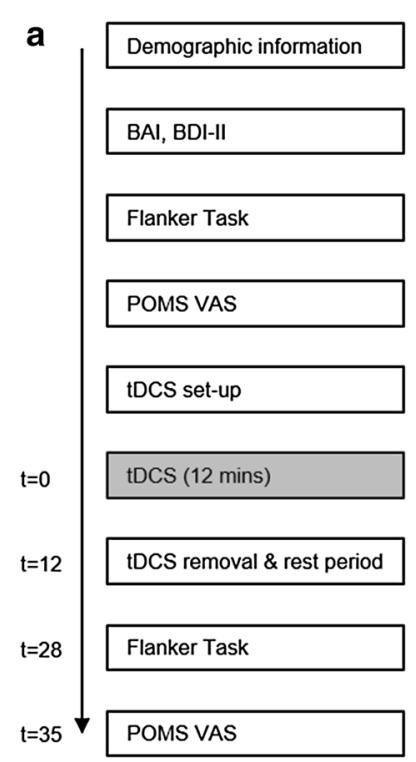

Fig. 1 Schematic of the study timeline. a Sessions 1 timeline: $B A I$ Beck Anxiety Inventory, BDI-II Beck Depression Inventory-II, POMS VAS profile of mood states-visual analogue scale, $t D C S$ transcranial direct current stimulation. b Schematic of the study timeline for tDCS sessions $1-3$, experiments 1 and 2. Data collection occurred on days 1 and 5 only, tDCS stimulation occurred on days 1,3 , and 5 
stimulation generated by a neuroConn tDCS stimulator (neuroConn GmBH, Germany).

Following completion of the stimulation, participants had a rest period of approximately $16 \mathrm{~min}$ (Merzagora et al. 2010). This was followed by a repetition of the Flanker Task and completion of the POMS-VAS. To prevent movement and disengagement during the experiment, between tasks, participants were requested to watch one of 4 nature documentaries (counterbalanced throughout the course of the trial; online resources, Sect. 7). At the end of the final session, participants received a verbal and written debrief.

\section{tDCS electrode placement}

Prior studies have utilised cerebellar stimulation paradigms involving either bilateral or right cerebellum hemisphere stimulation with the reference electrode situated on either the ipsilateral buccinator or shoulder (e.g. Ferrucci et al. 2012, 2013; Jayaram et al. 2012; Galea et al. 2009). In the present research, however, we make use of a stimulation montage in which one electrode is positioned over the left dIPFC (F3 position according to the 10-20 electrode system), whilst the opposing electrode is positioned over the contralateral lobe of the cerebellum. Placement for lateral stimulation of the cerebellum is determined as $1 \mathrm{~cm}$ down from the inion and approximately $3-3.5 \mathrm{~cm}$ away from the midline of the skull (Ferrucci et al. 2015; Hashimoto et al. 1995), such that the centre of the electrode is situated approximately over CRUS II and Lobule VII B portions of the cerebellum. We tailored the stimulation montage to target our brain regions of interest by generating theoretical models of current flow (Fig. 2) using the HD-Explore software (Soterix Medical, NY, USA), which uses a finite-element-method modeling approach to quantify electric field intensity throughout the brain (Datta et al. 2009).

In line with prior mood modulation work (Austin et al. 2016), stimulation was performed for a duration of $12 \mathrm{~min}$. In keeping with prior cerebellar stimulation studies (e.g. Block and Celnik 2013; Ferrucci et al. 2013; Shah et al. 2013), an intensity of $2 \mathrm{~mA}$ was used for active stimulation with a maximum output of $0.08 \mathrm{~mA} \mathrm{~cm}{ }^{2}$, a $15 \mathrm{~s}$ ramp-up period at the start, and a $15 \mathrm{~s}$ ramp-down period at the end. Sham stimulation delivered a total electrical load, of $5 \%$ of that given to the active condition. This consisted of a rampup period of $15 \mathrm{~s}$ (at $0.13 \mathrm{~mA} \mathrm{~s}^{-1}$ ) to realistically simulate an active stimulation by inducing the tingling sensation often felt during the start of the tDCS stimulation (Brunoni et al. 2012b; Kessler et al. 2012), a plateau period of 6 s, and a ramp-down period of $15 \mathrm{~s}$. The attachment of the wires to the electrodes were positioned such that they were vertically oriented and directing the wire downwards. Electrode impedance of less than $5 \mathrm{k} \Omega$ was ensured before stimulation began. The tDCS device included a feature to automatically cease stimulation if impedance became too high; this did not occur during any stimulations.

\section{Mood assessment}

The profile of mood states (POMS) (McNair et al. 1971) questionnaire provides a rapid method of assessing transient, fluctuating active mood states. It is an instrument particularly well suited to the present research because of its sensitivity to change in affective states. Six visual analogue scales (VAS) were derived from dimensional analysis of the 72-question, bipolar POMS questionnaire (Lorr et al. 1982; McNair et al. 1971; O'Connell et al. 2012;

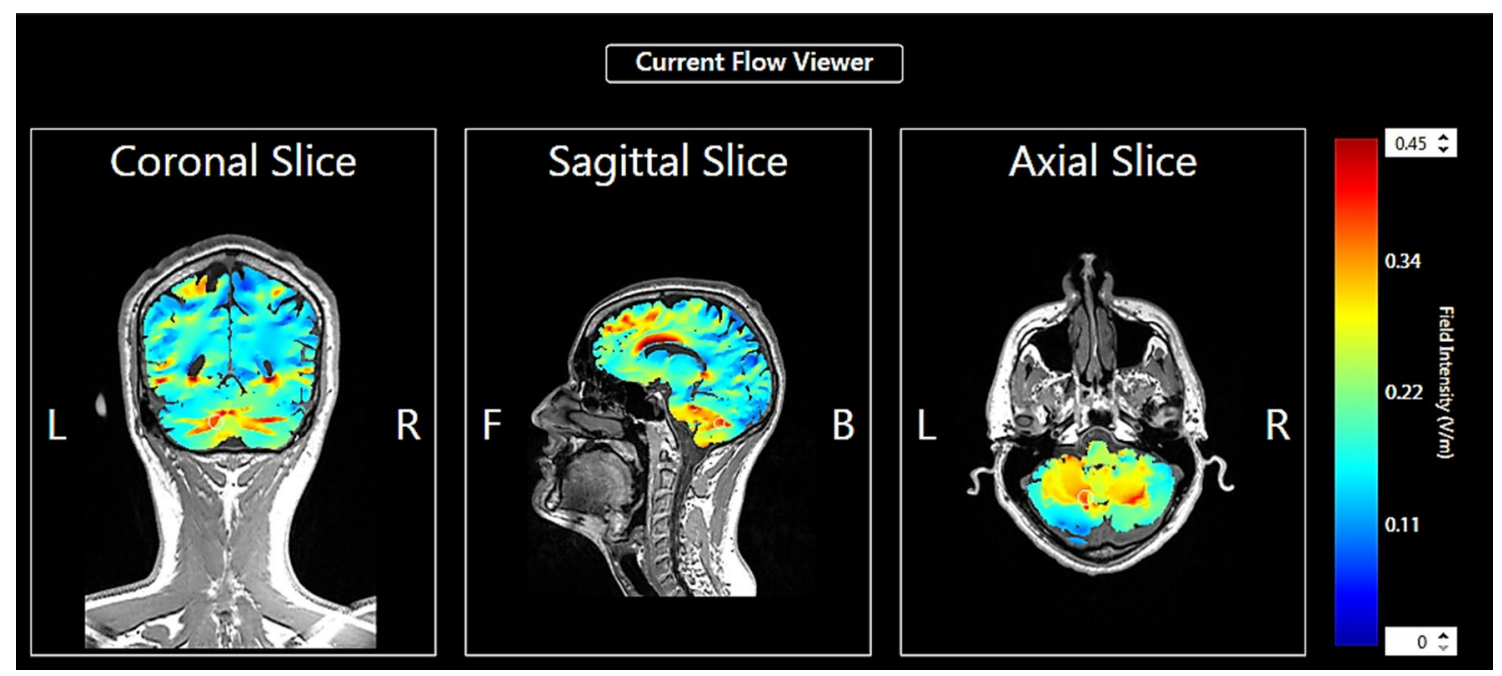

Fig. 2 Modelling of the electric field intensity. Modelling uses a standard brain, for the pad electrode placement targeting the left dlPFC (anode) and right cerebellum (cathode) 
O'Halloran et al. 2004) (subsequently referred to as POMSVAS). Using a VAS to evaluate current mood has been repeatedly demonstrated to be valid and reliable (e.g. de Boer et al. 2004; Terry et al. 2003; Shacham 1983; Lee et al. 1991; Aitken 1969). Participants were asked to mark one vertical line across each of the six horizontal bipolar axes: agreeable-hostile; clearheaded-confused; composed-anxious; elated-depressed; confident-unsure; energetic-tired. Each VAS axis was $100 \mathrm{~mm}$ in length and scores (in $\mathrm{mm}$ ) were calculated from the right hand of the axis, such that an increased score indicated an elevation in positive mood attributes.

\section{Statistics}

All results were analysed using SPSS statistical analyses software for Windows (Version 22.0. Armonk, NY: IBM Corp.). Pearson's $X^{2}$ was used to assess distributions of gender and handedness, and a one-way ANOVA was employed in the assessment of the distribution of age, BMI, BDI-II scores, and BAI scores between conditions. Prior to analysis of the mood modulation data, composite scores from all dimensions of the POMS were calculated and averaged (subsequently referred to as POMS-VAS unless otherwise stated). Outliers were identified using the interquartile range with a multiplication factor of 2.2 (Hoaglin et al. 1986; Tukey 1977). Pearson's $r$ was used to investigate associations between baseline scores for BDI-II and BAI, which were examined against changes in POMS-VAS scores, and the corresponding individual dimensions of the POMS-VAS scale (i.e. elated-depressed, composed-anxious). Before analysing data from the Flanker attention task, averaged scores were calculated for separate response times of correctly answered congruent and incongruent trials. Additionally, the number of errors in response to congruent stimuli was calculated, as was the number of errors in response to incongruent stimuli and the total error rate across all valid trials.

Pre-stimulation on session 1 formed the baseline measurement for all subsequent measures (Austin et al. 2016). To measure the acute effects of stimulation on mood, and behavioural response to the Flanker Task, $2 \times 2$ mixed ANOVAs [Time (pre-stimulation/post-stimulation) $\times$ Condition (sham/ active)] were performed on all primary outcome measures, with time as within-subjects and condition as between-subjects factors. Follow-up $t$ tests were then used to investigate the effects of the within- and between-subjects factors on POMS-VAS and the individual dimensions of the POMS VAS. In Experiment 1, the effects of repeated stimulation upon mood were investigated with a $4 \times 2$ ANOVA [Time (pre-stimulation1/post-stimulation1/pre-stimulation3/poststimulation 3$) \times$ Condition (sham/active)] mixed ANOVA. Again, follow-up $t$ tests were employed to compare baseline measurements against subsequent time point, and for analysis of within-subjects effects of repeated stimulations. In Experiment 2, the effects of repeated stimulation upon mood were investigated with repeated-measures ANOVA of the 4-time points, and follow-up $t$ tests. Bonferroni corrections were applied where appropriate.

\section{Participants}

Seventy-nine healthy adults, aged between 18 and 40, participated in the experiment for either financial remuneration in the form of a $£ 10$ voucher or course credits. Fifty-three participants were randomly allocated into either Active; F3:Anode/ Cerebellum:cathode $[\mathrm{F} 3+/ \mathrm{Cb}-(n=28)$ or Sham $(n=24)$ conditions of Experiment 1 by use of a random number generator (random.org 2017). The remaining participants formed the Active condition; F3:Cathode/Cerebellum:anode (F3- $\mathrm{Cb}+)$ $(n=26)$ of Experiment 2 (See Table 1 for demographic clarification of participants included in inferential analyses].

Participants were naïve to the purpose of the study but were informed that it involved neuromodulation via tDCS and the completion of questionnaires and computer-based tasks. All participants signed written informed consent forms and completed a series of screening questionnaires to ensure they were neurologically and psychologically healthy, with no contraindications to tDCS. Exclusion criteria included experience of head trauma, seizures, psychological and/or neurological disorders, previous adverse experience with any form of neuromodulation, or the possession of an implant (for example, cochlea or a pacemaker). Side effects questionnaires were completed at the beginning of sessions 2 and 3. Follow-up side effect questionnaires were emailed out 1 week after cessation of participation. A tingling sensation was reported by all conditions ( $\mathrm{F} 3+/$ $\mathrm{Cb}-=3$, Sham $=2, \mathrm{~F} 3-/ \mathrm{Cb}+=5$ ), as was sleepiness ( $\mathrm{F} 3+/$ $\mathrm{Cb}-=5$, Sham $=5, \mathrm{~F} 3-/ \mathrm{Cb}+=5)$, and redness $(\mathrm{F} 3+/$ $\mathrm{Cb}-=1$, Sham $=1, \mathrm{~F} 3-/ \mathrm{Cb}+=4)$. Trouble concentrating $(\mathrm{F} 3+/ \mathrm{Cb}-=3$, Sham $=2)$ and headaches $(\mathrm{F} 3+/ \mathrm{Cb}-=3$, Sham $=4$ ) were only reported in Experiment 1, and acute mood change was reported in both active conditions (F3+l $\mathrm{Cb}-=2, \mathrm{~F} 3-/ \mathrm{Cb}+=1$ ), but not the Sham condition. All participants were given details of the University's Wellbeing services, as well as local branches of MIND, and the Samaritans. The departmental Research Ethics Committee of Swansea University approved all experimental procedures.

\section{Experiment 1}

\section{Participants for single stimulation}

Forty-four participants were included in the final analyses (Table 1). Of the 53 participants who completed the 
Table 1 Distribution of participants across conditions and experiments

\begin{tabular}{|c|c|c|c|c|c|c|c|c|c|c|}
\hline \multirow[t]{3}{*}{ Group } & \multirow[t]{3}{*}{ Measure } & \multicolumn{6}{|c|}{ Experiment 1} & \multirow{2}{*}{\multicolumn{3}{|c|}{$\frac{\text { Experiment } 2}{\mathrm{~F} 3-/ \mathrm{Cb}+\text { condition }}$}} \\
\hline & & \multicolumn{3}{|c|}{$\mathrm{F} 3+/ \mathrm{Cb}-$ condition } & \multicolumn{3}{|c|}{ Sham condition } & & & \\
\hline & & $n$ & $M$ & SD & $n$ & $M$ & SD & $n$ & $M$ & SD \\
\hline \multirow[t]{7}{*}{ Single stimulation: } & Participants & 21 & & & 23 & & & 23 & & \\
\hline & Female & 15 & & & 15 & & & 16 & & \\
\hline & Right hand dominant & 29 & & & 20 & & & 23 & & \\
\hline & Age & & 20.61 & 2.52 & & 23.09 & 5.65 & & 20.00 & 2.89 \\
\hline & BMI & & 23.41 & 3.66 & & 23.57 & 3.53 & & 22.73 & 3.69 \\
\hline & BDI-II & & 5.33 & 4.42 & & 5.87 & 3.11 & & 7.87 & 4.28 \\
\hline & BAI & & 3.67 & 2.92 & & 4.70 & 2.46 & & 6.21 & 4.06 \\
\hline \multirow[t]{7}{*}{ Repeated stimulation: mood } & Participants & 10 & & & 11 & & & 11 & & \\
\hline & Female & 6 & & & 5 & & & 8 & & \\
\hline & Right hand dominant & 9 & & & 9 & & & 11 & & \\
\hline & Age & & 20.4 & 2.95 & & 22.73 & 5.87 & & 20.27 & 4.00 \\
\hline & BMI & & 24.11 & 3.63 & & 23.80 & 3.82 & & 22.54 & 4.36 \\
\hline & BDI-II & & 6.4 & 4.55 & & 7.18 & 3.71 & & 9.36 & 4.70 \\
\hline & BAI & & 3.6 & 3.09 & & 5.64 & 2.66 & & 6.72 & 5.0 \\
\hline
\end{tabular}

experiment, one was excluded from the Sham condition for exceeding the imposed limitations of BAI and/or BDI-II scores for mild anxiety (BAI $\leq 16$, Creamer et al. 1995) and mild depression (BDI-II $\leq 19$, Beck et al.1996) and seven were excluded from the $\mathrm{F} 3+/ \mathrm{Cb}-$ condition: two were excluded due to a malfunction that resulted in excess heat within the laboratory during their data collection, one after being identified as an extreme outlier, and four for exceeding the imposed limitations of BAI and/ or BDI-II scores (see "Shortcomings and future directions"). Both gender $\left(X^{2}=.195, p=.659\right)$ and handedness $\left(X^{2}=.135, p=.713\right)$ were closely matched between the two conditions. There were no significant differences of age $[F(1,42)=3.388, p=.073]$, BMI distribution $[F(1,42)=.007, p=.934]$, BAI scores $[F(1,42)=1.608$, $p=.212]$, or BDI-II scores $[F(1,42)=.220 p=.642]$ between the two conditions.

\section{Participants for repeated stimulation}

Twenty-one participants completed the three stimulation trial (Table 1). There were no significant differences of gender (Fischer exact test $p=.670$ ), handedness (Fischer exact test $p=1.0$ ), age $[F(1,19)=1.276$, $p=.273]$, BMI distribution $[F(1,19)=.037, p=.849]$, BAI $[F(1,19)=2.630, p=.121]$, or BDI-II scores $[F(1,19)=.188, p=.670]$ between the two conditions of Experiment 1.

\section{Experiment 2}

\section{Participants for single stimulation}

Twenty-Three participants were included in inferential analysis (Table 1) one being excluded due identification as an extreme outlier, and two for failing to sufficiently engage with the Flanker Task. No differences in gender $\left(X^{2}=.210\right.$, $p=.900)$, handedness $\left(X^{2}=3.021, p=.221\right)$ or BMI distribution $[F(2,64)=.344, p=.710]$ were observed among all 3 conditions of both experiments. There was, however, a significant difference of age between all conditions $[F(2,64)=3.852, p=.026]$ namely, however, this was only between the $\mathrm{F} 3-/ \mathrm{Cb}+$ condition and the Sham condition $[F(1,44)=5.443, p=.024]$, but not between the $\mathrm{F} 3+/$ $\mathrm{Cb}-$ condition and the $\mathrm{F} 3-/ \mathrm{Cb}+$ condition $[F(1,42)=.568$, $p=.455]$. Additionally, age was not associated with the primary outcome measures for the $\mathrm{F} 3-/ \mathrm{Cb}+$ condition (POMSVAS score change: $n=23, r=.22, p=.31$ ), suggesting that age exerted no influence over the observed effects.

There was no significant difference of BDI-II scores between all three conditions $[F(2,64)=2.546, p=.086]$, although a significant difference between BAI scores was observed $[F(2,64)=3.502, p=.036]$. Further investigation revealed that this was between the $\mathrm{F} 3+/ \mathrm{Cb}-$ condition and the $\mathrm{F} 3-/ \mathrm{Cb}+$ condition $[F(1,42)=5.632, p=.022]$, but not the $\mathrm{F} 3-/ \mathrm{Cb}+$ condition and the Sham condition $[F(1,44)=2.368, p=.131]$. However, BAI scores were not associated with the primary outcome measure for the 
F3-/Cb+ condition (POMS-VAS score change: $n=23$, $r=.30, p=.17)$.

\section{Participants for repeated stimulation}

Eleven participants (Table 1) were analysed on selfreported measures of mood with the POMS-VAS. Gender $\left(X^{2}=1.698, p=.428\right)$ and handedness $\left(X^{2}=2.147, p=.342\right)$ showed no significant difference in distribution between the F3-/Cb+ condition of Experiment 2 and the two groups of Experiment 1. Again, no significant difference of age distribution $[F(2,29)=1.031, p=.369]$, BMI distribution $[F(2,29)=.477, p=.625]$, BAI scores $[F(2,29)=1.865$, $p=.173]$, or BDI-II scores $[F(2,29)=1.339, p=.278]$ were observed between all groups across both experiments.

\section{Results}

BAI scores correlated significantly with baseline POMSVAS scores $(n=67, r=-.31, p=.01)$ as well as with baseline scores of the individual POMS-VAS dimension of composed-anxious ( $n=67, r=-.26, p=.032)$. BDI-II scores also correlated significantly with baseline POMSVAS scores ( $n=67, r=-.36, p=.003$ ), and with baseline measurements of the individual POMS-VAS dimension of Elated-Depressed $(n=67, r=-.44, p<.001)$. However, for the active conditions $\mathrm{F} 3+/ \mathrm{Cb}-$ and $\mathrm{F} 3-/ \mathrm{Cb}+$, there was no association between baseline BAI scores and change of POMS-VAS scores $(n=21, r=-.27, p=.23)$ and $(n=23$, $r=-.30, p=.17$ ), respectively, or baseline BDI-II scores and change of POMS-VAS scores $(n=21, r=-.08, p=.73)$ and $(n=23, r=-.02, p=.94)$, respectively.

\section{Influence of Single Stimulation Over POMS-VAS Scores}

Experiment 1: To examine the acute effects of tDCS stimulation upon mood we initially conducted a $2 \times 2$ ANOVA on POMS-VAS scores. A main effect of Time was observed $[F(1,42)=6.742, p=.01$, observed power $=.718]$, but no main effect of Condition was present $[F(1,42)=2.678$, $p=.11$, observed power $=.359]$. However, we did observe a significant Time $\times$ Condition interaction $[F(1,42)=6.170$, $p=.02$, observed power $=.680]$. In addition, we observed a significant increase in POMS-VAS scores from preto post-stimulation for the Active $\mathrm{F} 3+/ \mathrm{Cb}-$ condition $[t(20)=4.481, p=<.001$, Cohen's $d=.62]$, but not for the Sham condition $[t(22)<1]$. We observed no statistical difference between POMS-VAS scores for the two conditions at pre-stimulation $[t(42)<1]$, but we did observe a difference at post-stimulation $[t(42)=2.230, p=.03]$ (Fig. 3).
Pre-tDCS
Post-tDCs

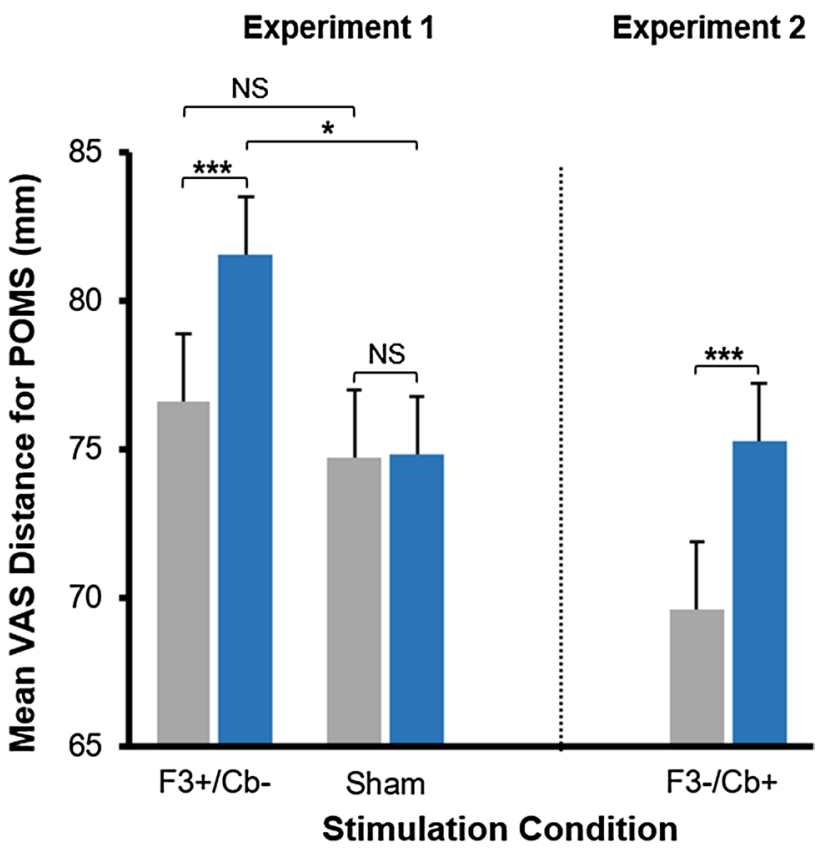

Fig. 3 Single stimulation POMS-VAS analysis for Experiments 1 and $2(* p \leq .05 ; * * p \leq .01 ; * * * \leq .001)$

Experiment 2: For the acute effects of the reversed polarity tDCS electrode placement upon mood, we observed a significant increase in POMS-VAS scores between pre- and post-stimulation for the $\mathrm{F} 3-/ \mathrm{Cb}+$ condition $[t(22)=3.820$, $p=.001$, Cohen's $d=.56$ ] (Fig. 3). See online resources, Sect. 2 for table of mean \pm standard deviation, and Sect. 3 for examination of the POM-VAS dimensions.

Experiment 1, results of paired and independent $t$ tests for $\mathrm{F} 3+/ \mathrm{Cb}-(n=21)$ and Sham conditions $(n=23)$. Experiment 2, results of paired t test: $\mathrm{F} 3-/ \mathrm{Cb}+$ condition $(n=23)$, pre- and post-stimulation.

\section{Influence of Repeat Stimulation Over POMS-VAS Scores}

Experiment 1: Over successive stimulations, we observed a progressive increase in mean $\mathrm{F} 3+/ \mathrm{Cb}-$ POMS-VAS scores that was not present in the sham condition. To examine the effect of repeated stimulation upon mood, a 4x2ANOVA [Time (Pre-stimulation1/Post-stimulation1/ Pre-stimulation3/Post-stimulation3) $\times$ Condition $(\mathrm{Sham} /$ Active)] was employed. A main effect of Time was present $F(3,57)=3.719, p=.009$, observed power $=.836]$, but there was no main effect of Condition $F(1,19)=3.295, p=.085$, observed power $=.407]$. However, we did observe a significant Time $\times$ Condition interaction $[F(3,57)=3.719$, $p=.016$, observed power $=.780]$. Independent $t$ 
tests revealed no significant difference between F3 +/ $\mathrm{Cb}-$ and Sham conditions for POMS-VAS scores at baseline $[t(19)<10]$, post-stimulation $[t(19)=1.612, p=.61]$, or pre-stimulation3 $[t(19)=1.851, p=.78]$. We did, however, observe a significant difference between conditions for post-stimulation3 $[t(19)=2.459, p=.024$, Cohen's $d=1.09]$. Additionally, follow-up $t$ tests revealed significant differences for POMS-VAS measurements in the F $3+/$ $\mathrm{Cb}$ - condition between baseline and post-stimulation 1 $[t(9)=3.254, p=.010$, Cohen's $d=.36]$; pre-stimulation 3 $[t(9)=3.652, p=.005$, Cohen's $d=.61]$; and post-stimulation3 $[t(9)=4.368, p=.002$, Cohen's $d=.74]$ (Fig. 4). All comparisons to baseline survived post hoc analyses with Bonferroni correction $(p<.016)$. We found no significant change between baseline and further measurements in the sham condition (Fig. 4). No significant change was observed between pre-stimulation 3 and post-stimulation 3 for either the $\mathrm{F} 3+/ \mathrm{Cb}-[t(9)=1.667, p=.130]$, or the Sham $[t(10)=1.170, p=.269]$ condition.

Experiment 2: Over successive stimulations, we observed a progressive increase in mean $\mathrm{F} 3-/ \mathrm{Cb}+$ POMS-VAS scores $[F(3,30)=4.172 p=.014$, observed power $=.803]$. Paired $t$ tests revealed significant differences for POMS-VAS measurements in the $\mathrm{F} 3-/ \mathrm{Cb}+$ condition between baseline and post-stimulation $1 t(10)=3.38, p=.008$, Cohen's $d=.76]$; pre-stimulation3 $[t(10)=2.552, p=.029$, Cohen's $d=.57]$; and post-stimulation $3[t(10)=2.877, p=.016$, Cohen's

Baseline $\square$ Post-1 $\square$ Pre-3 $\square$ Post-3

Experiment 1

Experiment 2

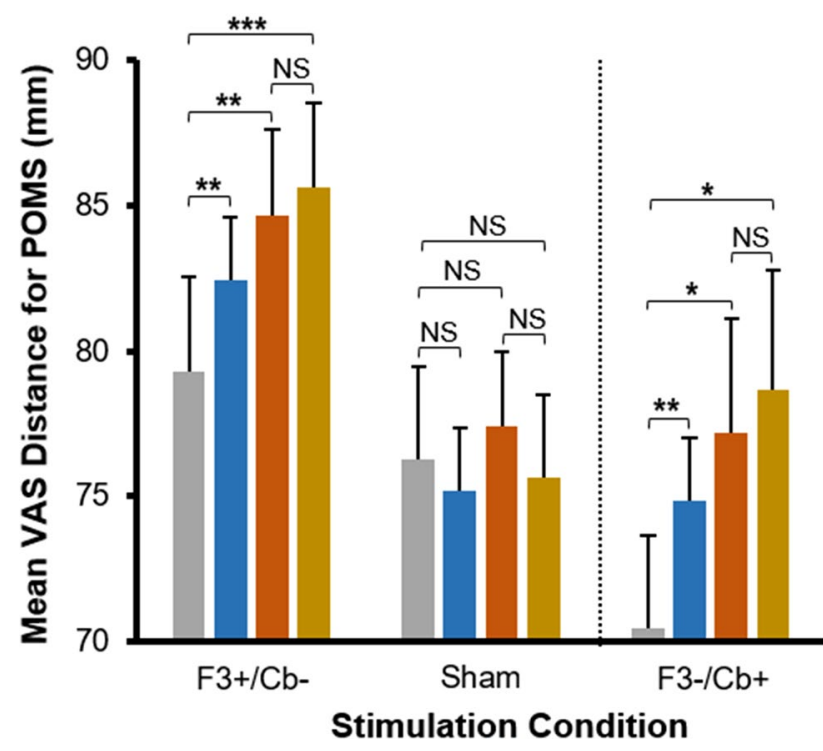

Fig. 4 Repeat stimulation POMS-VAS analysis for Experiments 1 and $2(* p \leq .05 ; * * p \leq .01 ; * * * p \leq .001)$ $d=.67$ ] (Fig. 4). Only comparisons of post-stimulation 1 and post-stimulation 3 to baseline survived post hoc analysis with Bonferroni correction $(p<.016)$. No significant change was present between pre-stimulation 3 and post-stimulation3 $[t(10)=2.048, p=.068]$. See online resources, Sect. 4 for table of mean \pm standard deviation, $t, p$, and $d$ values, and Sect. 5 for examination of individual POMSVAS dimensions.

Experiment 1, results of paired and independent $t$ tests for $\mathrm{F} 3+/ \mathrm{Cb}-(n=10)$ and Sham $(n=11)$ conditions. Experiment 2 , results of paired $t$ test: $\mathrm{F} 3-/ \mathrm{Cb}+$ condition $(n=11)$.

\section{Flanker task}

No significant interactions were observed either single or repeat stimulation experiments. See online resources, Sect. 6 for table of mean \pm standard deviation, and results.

\section{Discussion}

The present research demonstrates that single or repeated sessions of frontocerebellar tDCS constitute an effective strategy to positively modulate mood. Following a single stimulation session, a mood improvement of approximately $5 \%$ was observed in both the $\mathrm{F} 3+/ \mathrm{Cb}-$ condition of Experiment 1 and again in the $\mathrm{F} 3-/ \mathrm{Cb}+$ of Experiment 2. No significant change was noted in the Sham condition. Additionally, we demonstrated a successive elevation of mood from baseline in both experiments following three stimulations delivered second-daily over the course of 5 days, with a total increase of mood from baseline of $>6 \%$ for the $\mathrm{F} 3+/ \mathrm{Cb}-$ condition and $>8 \%$ for the $\mathrm{F} 3-/ \mathrm{Cb}+$ condition. A significant mood increase was again observed between pre-/post-stimulation1 for both active conditions of repetitive stimulation analysis. A non-significant increase was observed between pre- and post-stimulation 3. As we used healthy participants, it is possible this lack of significance may reflect an approach to a ceiling with regard to mood measures.

A significant difference between BAI scores was observed between the active conditions $\mathrm{F} 3+/ \mathrm{Cb}-$ and $\mathrm{F} 3-/ \mathrm{Cb}+$. However, whilst BAI and BDI-II scores both correlated significantly with baseline measures of POMS-VAS, there was no correlation between these scores and the degree of mood change, making it unlikely that the observed changes in Experiment 2 were driven by baseline levels of anxiety.

It must be considered that the differences in baseline levels between Experiment 1 and Experiment 2 may be driving the effect observed in the $\mathrm{F} 3-/ \mathrm{Cb}+$ reverse polarity montage. It is not possible for us to directly compare the results from these two experiments, however, it should be noted that data collection occurred at different times of the year. As 
season variation has been shown to impact upon a number of endocrine functions which influence mood and level of psychological arousal (Hansen et al. 2008, 2001; Lam and Levitan 2000; Persson et al. 2008), it is possible that had data collection occurred during the same seasonal period we would still have observed an equivalent POMS-VAS baseline in the $\mathrm{F} 3-/ \mathrm{Cb}+$ condition of Experiment 2, and still observed the same degree of mood increase.

Whilst not conclusive, there is some evidence to suggest an absence of polarity specific effects for mood modulation which warrant further investigation. Baseline levels of mood for the $\mathrm{F} 3-/ \mathrm{Cb}+$ condition of Experiment 2 are approximately 7\% lower than those of either condition of Experiment 1. Following single stimulation the observed increase of mood for the F3-/Cb+ condition only slightly exceeds both pre and post-stimulation scores of the Sham condition. However, following repeated stimulation there is an elevation from baseline at all points of data collection for the F3-/Cb+ condition of Experiment 2 which is equivalent too or exceeds the greatest POMS-VAS score for the Sham condition. Additionally, comparison of the POMS-VAS dimensions exhibits an almost paralleled change across all dimensions for both Active conditions, but not for the Sham conditions. This is most is obvious following single stimulation (See online resources, Sect. 3) but is also present, albeit to a lesser degree, in dimensional analyses for repeated stimulation (See online resources, Sect. 3).

Whilst it may be intuitive to expect that polarity would influence the effects of the montage, as some evidence supports the classical notion of the influence of polarity upon neuronal excitability (e.g. Datta et al. 2009), this is perhaps somewhat over-simplistic. Orientation of somatodendritic axis and the distance of the axon to the locally applied direct current has resulting cellular influences (Holsheimer et al. 2007; Bikson et al. 2004; Gluckman et al. 1996) and can determine whether the applied field has an excitatory or inhibitory influence (Kabakov et al. 2012). Additionally, the physiological effects of the stimulation extend beyond the influence of electrode polarity and neuronal orientation and are also determined by whether the predominant influence of the affected network is excitatory or inhibitory (Lefaucheur et al. 2017).

Other considerations when examining polarity induced effects include stimulation intensity and current density at the electrode (Faria et al. 2011; Miranda et al. 2009, 2006). Increases in the amplitude of cathodal stimulation, from 1 to $2 \mathrm{~mA}$, have been shown to induce (motor) cortical excitability enhancement, reflective of anodal stimulation (Batsikadze et al. 2013). Additionally, cortical folding produces polarity inversions of current flow and gyri and sulci produce the potential for current clustering (Datta et al. 2009; Sadleir et al. 2010). The cerebellum possesses both a disproportionally high density of neurons (Herculano-Houzel
2009), many of which are GABAergic (Galea et al. 2009; Pope and Miall 2012), and a large degree of cortical folding (Herculano-Houzel 2009). Therefore, whilst certain limitations of the study prevent us from drawing definitive conclusions, it is perhaps not surprising that at $2 \mathrm{~mA}$ polarity appears to have little, if any, influence over the degree to which mood was modulated.

To the best of our knowledge, the present study is the first to successfully demonstrate mood modulation in healthy subjects, in response to both single, and repeated, administration of tDCS. This may be partly attributable to methodological differences. In this research we used a VAS derived from the bipolar POMS questionnaire, whereas other studies [e.g. (Bennabi et al. 2015; Brunoni et al. 2013; Loo et al. 2010)] have used methods such as the Montgomery Asberg Depression Rating Scale, or the Hamilton Depression Rating Scale. Whilst reliable when assessing individuals with depression, the latter measures are perhaps not sensitive enough to detect transient fluctuations in mood of healthy individuals.

Another consideration is the time at which we assessed mood: It seems common practice to administer the measures immediately before (baseline) and following stimulation (e.g. Nitsche et al. 2012; Peña-Gómez et al. 2011; Plazier et al. 2012; Vanderhasselt et al. 2013), although Fregni et al. (2008) completed the final evaluation approximately 10 min after stimulation cessation, while Tadini et al. (2011) completed the final assessment approximately post 20 min. We administered the post-stimulation POMS-VAS at approximately $25 \mathrm{~min}$ post stimulation-cessation. Motor cortex studies have demonstrated peak MEP amplitudes occurring approximately $90 \mathrm{~min}$ after stimulation (e.g. Batsikadze et al. 2013). It is possible that the convention timing of re-assessment following tDCS does not allow for a sufficient period to detect tDCS-induced modulations of mood. Duration of stimulation may also contribute to differences in findings.

In our previous research (Austin et al. 2016) as in the current one, we used a stimulation duration of $12 \mathrm{~min}$. Many prior studies, however (e.g. Bennabi et al. 2015; Brunoni et al. 2013; Fregni et al. 2008; Motohashi et al. 2013) used stimulation durations of 20 min or more. However, modulatory effects lasting approximately $1 \mathrm{~h}$ have been demonstrated for tDCS stimulation durations of 10 min (Fricke et al. 2011; Furubayashi et al. 2008; Nitsche and Paulus 2001) and a nonlinear influence has been demonstrated between stimulation duration and potentiated effect (MonteSilva et al. 2013).

Frontocerebellar stimulation has previously been investigated in conjunction with a number of pathologies, however, differences such as electrode size and position exist between the montages previously used and the one utilised within the present research. For example, in the case of Ho et al. 
(2014), a $5 \mathrm{~cm} \times 7 \mathrm{~cm}$ electrode was positioned over the left supraorbital region, while a large $5 \mathrm{~cm} \times 10 \mathrm{~cm}$ cathode was situated centrally over the cerebellum. Here, we used the same $5 \times 5 \mathrm{~cm}\left(25 \mathrm{~cm}^{2}\right)$ electrode size as Minichino et al. (2014). However, whilst identification of the site of cerebellar stimulation was comparable, we identified the dIPFC as situated under the position of F3 of the 10-coordinate system, whereas Minichino et al. (2014) used the less conventional position of Fp1. Since tDCS relies on the presence of both polarity electrodes, current must always enter and exit the cortex via intermediary brain regions. Even small variations of electrode placement and size can influence tDCS field distribution (Saturnino et al. 2015; Faria et al. 2011; Miranda et al. 2009).

Without supporting physiological and/or neuroimaging data, it is only possible to speculate about the mechanism which might be responsible for this mood modulation. Previous mood modulation investigation has restricted the flow of current to the prefrontal cortices. Increased distance between electrodes reduces the degree of shunting across the scalp, increasing the amount of current which enters the brain (Bikson et al. 2010). In support of this, the computational model (Fig. 2) indicated particularly high current density in one area of the limbic system: the anterior cingulate cortex (ACC). Levels of ACC activity have been correlated with severity of depressive symptoms and treatment outcomes (Downey et al. 2016; Mayberg et al. 1997; Osuch et al. 2000), and deep brain stimulation of the ACC has demonstrated amelioration from treatment resistant depression (Anderson et al. 2012; Holtzheimer and Mayberg 2012; Mayberg 2009).

By directing the current contralaterally from the posterior to the anterior of the brain (or visa-versa), there is perhaps a greater chance of modulating neural activity in structures associated with affective processes and arousal. For example, the cerebellum has demonstrated reciprocal connections with brainstem regions linked to limbic and paralimbic regions (Snider and Maiti 1976), the hypothalamus (Aas and Brodal 1988; Haines et al. 1984), as well as brainstem regions that participate in the modulation of autonomic function (Almeida et al. 2002; Golanov et al. 2000; Andrezik et al. 1984; Miura and Reis 1969).

\section{Shortcomings and future directions}

Aside from the fact that data for all three conditions were not collected within the one experiment, the current research presents several limitations. Firstly, blinding may have been inadequately assessed. Whilst some studies have assessed the sham protocol as a suitable blind for tDCS studies using $1 \mathrm{~mA}$ (Gandiga et al. 2006), the experience of sensory side effects such as itching have been shown to be more prevalent in the active than the sham condition at $1.5 \mathrm{~mA}$ (Kessler et al. 2012). Additionally, it has been suggested that sham stimulation at $2 \mathrm{~mA}$ is an inadequate blinding procedure (O'Connell et al. 2012; Wallace et al. 2016). However, it should be noted that both studies utilised a within-subjects design, but despite this aspect a bias towards selection of the Active condition (85\%) was demonstrated in the latter (Wallace et al. 2016), and correct identification following both sham and active stimulation conditions did not exceed $65 \%$ (O'Connell et al. 2012). As recorded side effects between the conditions of our experiment were comparable, we feel confident that our between-subjects research was suitably blinded. However, as we did not technically assess the reliability of our blinding procedure, it would be remiss to not at least acknowledge the possibility that the observed effects may, in part, be attributable to insufficient blinding.

Second, sample size also presented some limitations. Our decision to retrospectively exclude participants based on BAI and BDI-II scores reduced an already relatively small sample size. We made a priori assumptions regarding our sample and anticipated conducting an intention to treat analysis of psychologically healthy individuals. However, across both experiments, a greater number of participants (4 from the active condition of Experiment 1 and one from the sham condition) exceeded the scores for mild anxiety (BAI $\leq 16$ $\mathrm{REF})$ and depression (BDI-II $\leq 19 \mathrm{REF}$ ). Despite the fact that each of these participants who received an active stimulation reported an increase in mood, we considered that they should be removed from the sample for analyses to keep the focus of this research on individuals with sub-clinical levels of depression and/or anxiety, which may have been seen as driving the results observed in the active condition of Experiment 1.

Finally, we opted to replicate a previous second-daily design, of 3 repeat stimulations, which had demonstrated significant mood improvements for the F3 anode/F4 cathode electrode placement (Austin et al. 2016). Whilst direct comparisons cannot be made between the current research and prior studies conducted on a sample of depressed individuals, it is worth bearing in mind that daily stimulation is the norm for the latter (see Dedoncker et al. 2016). Additionally, it has been demonstrated that daily tDCS results in a greater increase in MEP amplitude than second-daily (Alonzo et al. 2012). Perhaps we would have observed a greater increase of mood improvement if we had opted for consecutive days.

\section{Conclusion}

We have presented evidence of mood modulation using a short duration frontocerebellar stimulation montage in response to single and repeated administration. Further investigations are needed, both to confirm the presence or absence of polarity specificity, and to establish specificity 
regarding the mechanisms by which frontocerebellar stimulation exerts influence over mood. Future experiments might consider refining the application of frontocerebellar tDCS by incorporating neuroimaging techniques. In general, tDCS displays promise as a therapeutic intervention. However, there is a need for further clinical exploration, technical development, and replication of earlier findings (as highlighted by Tortella et al. 2015) to further elucidate the potential applications of various tDCS stimulation paradigms as stand-alone or adjunctive treatments for mood, affective and psychopathological disorders.

Acknowledgements We would like to thank Mr. G. Freegard for his technical support, and in particular his work in the development of the Flanker Task.

\section{Compliance with ethical standards}

Conflict of interest Author FB holds shares in NeuroActive Medical Ltd. The other authors declare that the research was conducted in the absence of any commercial or financial relationships that could be construed as a potential conflict of interest.

Open Access This article is distributed under the terms of the Creative Commons Attribution 4.0 International License (http://creativecommons.org/licenses/by/4.0/), which permits unrestricted use, distribution, and reproduction in any medium, provided you give appropriate credit to the original author(s) and the source, provide a link to the Creative Commons license, and indicate if changes were made.

\section{References}

Aas J-E, Brodal P (1988) Demonstration of topographically organized projections from the hypothalamus to the pontine nuclei: an experimental anatomical study in the cat. J Comp Neurol 268(3):313-328. doi:10.1002/cne.902680303

Adamaszek M, D’Agata F, Ferrucci R, Habas C, Keulen S, Kirkby KC, Verhoeven J (2017) Consensus paper: cerebellum and emotion. Cerebellum 16(2):552-576. doi:10.1007/s12311-016-0815-8

Aitken RC (1969) Measurement of feelings using visual analogue scales. In: Proceedings of the Royal Society of Medicine, 62(10):989-93. http://www.ncbi.nlm.nih.gov/pubmed/4899510. Accessed 25 Aug 2016

Almeida A, Cobos A, Tavares I, Lima D (2002) Brain afferents to the medullary dorsal reticular nucleus: a retrograde and anterograde tracing study in the rat. Eur J Neurosci 16(1):81-95. doi:10.1046/j.1460-9568.2002.02058.x

Alonzo A, Brassil J, Taylor JL, Martin D, Loo CK, Loo AAJBJLTDMCK (2012) Daily transcranial direct current stimulation (tDCS) leads to greater increases in cortical excitability than second daily transcranial direct current stimulation. Brain Stimul 5(3):208-213. doi:10.1016/j.brs.2011.04.006

Amico F, Meisenzahl E, Koutsouleris N, Reiser M, Möller H-J, Frodl T (2011) Structural MRI correlates for vulnerability and resilience to major depressive disorder. J Psychiatry Neurosci. doi:10.1503/ jpn.090186

Anderson RJ, Frye MA, Abulseoud OA, Lee KH, McGillivray JA, Berk M, Tye SJ (2012) Deep brain stimulation for treatmentresistant depression: efficacy, safety and mechanisms of action.
Neurosci Biobehav Rev 36(8):1920-1933. doi:10.1016/j. neubiorev.2012.06.001

Andrezik JA, Dormer KJ, Foreman RD, Person RJ (1984) Fastigial nucleus projections to the brain stem in beagles: pathways for autonomic regulation. Neuroscience 11(2):497-507. http://www. ncbi.nlm.nih.gov/pubmed/6201783. Accessed 07 Jan 2016

Austin A, Jiga-Boy GM, Rea S, Newstead SA, Roderick S, Davis NJ, Boy F (2016) Prefrontal electrical stimulation in non-depressed reduces levels of reported negative affects from daily stressors. Front Psychol 7:315. doi:10.3389/fpsyg.2016.00315

Bation R, Poulet E, Haesebaert F, Saoud M, Brunelin J (2016) Transcranial direct current stimulation in treatment-resistant obsessive-compulsive disorder: an open-label pilot study. Prog Neuropsychopharmacol Biol Psychiatry 65:153-157. doi:10.1016/j. pnpbp.2015.10.001

Batsikadze G, Moliadze V, Paulus W, Kuo M-F, Nitsche MA (2013) Partially non-linear stimulation intensity-dependent effects of direct current stimulation on motor cortex excitability in humans. J Physiol 591(7):1987-2000. doi:10.1113/jphysiol.2012.249730

Baxter LR, Schwartz JM, Phelps ME, Mazziotta JC, Guze BH, Selin CE, Sumida RM (1989) Reduction of prefrontal cortex glucose metabolism common to three types of depression. Arch Gener Psychiatry 46(3):243-50. http://www.ncbi.nlm.nih.gov/pubmed/2784046. Accessed 17 July 2017

Beck AT, Steer RA, Brown GK (1996) Beck Depression Inventory II. Psychological Corporation, San Antonio

Bennabi D, Nicolier M, Monnin J, Tio G, Pazart L, Vandel P, Haffen E (2015) Pilot study of feasibility of the effect of treatment with tDCS in patients suffering from treatment-resistant depression treated with escitalopram. Clin Neurophysiol 126(6):1185-1189. doi:10.1016/j.clinph.2014.09.026

Berman AJ, Berman D, Prescott JW (1974) The effect of cerebellar lesions on emotional behavior in the rhesus monkey. In: The cerebellum, epilepsy, and behavior. Springer US, Boston, pp 277-284. doi:10.1007/978-1-4613-4508-4_12

Berrnan AJ (1997) Amelioration of aggression: response to selective cerebellar lesions in the rhesus monkey. pp 111-119. doi:10.1016/S0074-7742(08)60349-9

Bersani FS, Minichino A, Fattapposta F, Bernabei L, Spagnoli F, Mannarelli D, Delle Chiaie R (2015) Prefrontocerebellar transcranial direct current stimulation increases amplitude and decreases latency of P3b component in patients with euthymic bipolar disorder. Neuropsychiatric Dis Treat 11:2913-2917. doi:10.2147/ NDT.S91625

Bikson M, Inoue M, Akiyama H, Deans JK, Fox JE, Miyakawa H, Jefferys JGR (2004) Effects of uniform extracellular DC electric fields on excitability in rat hippocampal slices in vitro. J Physiol 557(1):175-190. doi:10.1113/jphysiol.2003.055772

Bikson M, Datta A, Rahman A, Scaturro J (2010) Electrode montages for tDCS and weak transcranial electrical stimulation: role of \&quot; return \&quot; electrode's position and size. Clin Neurophysiol. doi:10.1016/j.clinph.2010.05.020

Block H, Celnik P (2013) Stimulating the cerebellum affects visuomotor adaptation but not intermanual transfer of learning. Cerebellum 12(6):781-793. doi:10.1007/s12311-013-0486-7

Blumberger DM, Mulsant BH, Fitzgerald PB, Rajji TK, Ravindran AV, Young LT, Daskalakis ZJ (2012) A randomized double-blind sham-controlled comparison of unilateral and bilateral repetitive transcranial magnetic stimulation for treatment-resistant major depression. World J Biol Psychiatry 13(6):423-435. doi:10.310 9/15622975.2011.579163

Boggio PS, Rigonatti SP, Ribeiro RB, Myczkowski ML, Nitsche MA, Pascual-Leone A (2008) A randomized, double-blind clinical trial on the efficacy of cortical direct current stimulation for the treatment of major depression. Int J Neuropsychopharmacol 11(2):799-808. doi:10.1017/S1461145707007833 
Bradnam LV, Graetz LJ, McDonnell MN, Ridding MC (2015) Anodal transcranial direct current stimulation to the cerebellum improves handwriting and cyclic drawing kinematics in focal hand dystonia. Front Hum Neurosci 9:286. doi:10.3389/fnhum.2015.00286

Brooks JO, Hoblyn JC, Woodard SA, Rosen AC, Ketter TA, Leboyer M et al (2009) Corticolimbic metabolic dysregulation in euthymic older adults with bipolar disorder. J Psychiatr Res 43(5):497502. doi:10.1016/j.jpsychires.2008.08.001

Brunoni AR, Ferrucci R, Fregni F, Boggio PS, Priori A (2012a) Transcranial direct current stimulation for the treatment of major depressive disorder: a summary of preclinical, clinical and translational findings. Prog Neuropsychopharmacol Biol Psychiatry 39(1):9-16. doi:10.1016/j.pnpbp.2012.05.016

Brunoni AR, Nitsche MA, Bolognini N, Bikson M, Wagner T, Merabet L, Fregni F (2012b) Clinical research with transcranial direct current stimulation (tDCS): challenges and future directions. Brain Stimul 5(3):175-195. doi:10.1016/j.brs.2011.03.002

Brunoni AR, Valiengo L, Baccaro A, Zanão TA, de Oliveira JF, Goulart A, Fregni F (2013) The sertraline vs electrical current therapy for treating depression clinical study. JAMA Psychiatry 70(4):383. doi:10.1001/2013.jamapsychiatry. 32

Brunoni AR, Moffa AH, Fregni F, Palm U, Padberg F, Blumberger DM, Loo CK (2016) Transcranial direct current stimulation for acute major depressive episodes: meta-analysis of individual patient data. Br J Psychiatry 208(6):522-531. doi:10.1192/bjp. bp. 115.164715

Bueno VF, Brunoni AR, Boggio PS, Bensenor IM, Fregni F (2011) Mood and cognitive effects of transcranial direct current stimulation in post-stroke depression. Neurocase. doi:10.1080/13554 794.2010.509319

Chang C-C, Yu S-C, Mcquoid DR, Messer DF, Taylor WD, Singh K, Boyd BD, Krishnan KRK, MacFall JR, Steffens DC, Payne ME (2011) Reduction of dorsolateral prefrontal cortex gray matter in late-life depression. Psychiatry Res 193(1):1-6. doi:10.1016/j. pscychresns.2011.01.003

Charles ST, Piazza JR, Mogle J, Sliwinski MJ, Almeida DM (2013) The wear and tear of daily stressors on mental health. Psychol Sci 24(5):733-741. doi:10.1177/0956797612462222

Chisholm D, Sweeny K, Sheehan P, Rasmussen B, Smit F, Cuijpers P, Saxena S (2016) Scaling-up treatment of depression and anxiety: a global return on investment analysis. http://www.thelancet.com. doi:10.1016/S2215-0366(16)30024-4. Accessed 30 Jun 2016

Creamer M, Foran J, Bell R (1995) The Beck Anxiety Inventory in a non-clinical sample. Behav Res Ther 33(4):477-485. doi:10.1016/0005-7967(94)00082-U

Daskalakis ZJ, Levinson AJ, Fitzgerald PB (2008) Repetitive transcranial magnetic stimulation for major depressive disorder: a review. Can J Psychiatry 53(9):555-566. doi:10.1177/070674370805300902

Datta A, Bansal V, Diaz J, Patel J, Reato D, Bikson M (2009) Gyriprecise head model of transcranial direct current stimulation: Improved spatial focality using a ring electrode versus conventional rectangular pad. Brain Stimul 2(4):201-207.e1. doi:10.1016/j.brs.2009.03.005

Davidson RJ (2002) Anxiety and affective style: role of prefrontal cortex and amygdala. Biol Psychiat 51(1):68-80. doi:10.1016/ S0006-3223(01)01328-2

Davis K (2004) Decreased cortical gray and cerebral white matter in male patients with familial bipolar I disorder*1. J Affect Disord. doi:10.1016/j.jad.2004.03.010

de Boer AGEM, van Lanschot JJB, Stalmeier PFM, van Sandick JW, Hulscher JBF, de Haes JCJM, Sprangers MAG (2004) Is a singleitem visual analogue scale as valid, reliable and responsive as multi-item scales in measuring quality of life? Qual Life Res 13(2):311-320. doi:10.1023/B:QURE.0000018499.64574.1f
Dedoncker J, Brunoni AR, Baeken C, Vanderhasselt M-A (2016) A systematic review and meta-analysis of the effects of transcranial direct current stimulation (tDCS) over the dorsolateral prefrontal cortex in healthy and neuropsychiatric samples: influence of stimulation parameters. Brain Stimul 9(4):1-17. doi:10.1016/j. brs.2016.04.006

Downey D, Dutta A, McKie S, Dawson GR, Dourish CT, Craig K, Deakin JFW (2016) Comparing the actions of lanicemine and ketamine in depression: key role of the anterior cingulate. Eur Neuropsychopharmacol 26(6):994-1003. doi:10.1016/j. euroneuro.2016.03.006

Drevets WC, Bogers W, Raichle ME, Grunhaus L, Greden JF, Watson SJ, Charney DS (2002) Functional anatomical correlates of antidepressant drug treatment assessed using PET measures of regional glucose metabolism. Eur Neuropsychopharmacol J Eur Coll Neuropsychopharmacol 12(6):527-544. doi:10.1016/ S0924-977X(02)00102-5

Fales CL, Barch DM, Rundle MM, Mintun MA, Mathews J, Snyder AZ, Sheline YI (2008) Antidepressant treatment normalizes hypoactivity in dorsolateral prefrontal cortex during emotional interference processing in major depression. J Affect Disord 112:206-211. doi:10.1016/j.jad.2008.04.027

Faria P, Hallett M, Miranda PC (2011) A finite element analysis of the effect of electrode area and inter-electrode distance on the spatial distribution of the current density in tDCS. J Neural Eng 8(6):66017. doi:10.1088/1741-2560/8/6/066017

Ferrucci R, Bortolomasi M, Vergari M, Tadini L, Salvoro B, Giacopuzzi M, Priori A (2009) Transcranial direct current stimulation in severe, drug-resistant major depression. J Affec Dis. doi:10.1016/j.jad.2009.02.015

Ferrucci R, Giannicola G, Rosa M, Fumagalli M, Boggio PS, Hallett M, Priori A (2012) Cerebellum and processing of negative facial emotions: Cerebellar transcranial DC stimulation specifically enhances the emotional recognition of facial anger and sadness. Cognit Emot. doi:10.1080/02699931.2011.619520

Ferrucci R, Brunoni AR, Parazzini M, Vergari M, Rossi E, Fumagalli M, Priori A (2013) Modulating human procedural learning by cerebellar transcranial direct current stimulation. Cerebellum (Lond, Engl) 12(4):485-492. doi:10.1007/s12311-012-0436-9

Ferrucci R, Cortese F, Priori A (2015) Cerebellar tDCS: how to do it. Cereb (Lond, Engl) 14(1):27-30. doi:10.1007/ s12311-014-0599-7

Ferrucci R, Bocci T, Cortese F, Ruggiero F, Priori A (2016) Cerebellar transcranial direct current stimulation in neurological disease. Cereb Ataxias 3(1):16. doi:10.1186/s40673-016-0054-2

Fitzgerald PB, Benitez J, de Castella A, Daskalakis ZJ, Brown TL, Kulkarni J (2006) A randomized, controlled trial of sequential bilateral repetitive transcranial magnetic stimulation for treatment-resistant depression. Am J Psychiatry 163(1):88-94. doi:10.1176/appi.ajp.163.1.88

Fregni F, Ligouri P, Fecteau S, Nitsche MA, Pascual-Leone A, Boggio PS (2008) Cortical stimulation of the prefrontal cortex with transcranial direct current stimulation reduces cue-provoked smoking craving. J Clin Psychiatry 69(1):32-40. doi:10.4088/ JCP.v69n0105

Fricke K, Seeber AA, Thirugnanasambandam N, Paulus W, Nitsche MA, Rothwell JC (2011) Time course of the induction of homeostatic plasticity generated by repeated transcranial direct current stimulation of the human motor cortex. J Neurophysiol. http:// jn.physiology.org/content/105/3/1141.short. Accessed 29 Aug 2017

Furubayashi T, Terao Y, Arai N, Okabe S, Mochizuki H, Hanajima R, Ugawa Y (2008) Short and long duration transcranial direct current stimulation (tDCS) over the human hand motor area. Exp Brain Res 185(2):279-286. doi:10.1007/s00221-007-1149-Z 
Galea JM, Jayaram G, Ajagbe L, Celnik P (2009) Modulation of cerebellar excitability by polarity-specific noninvasive direct current stimulation. J Neurosci Off J Soc Neurosci 29(28):9115-9122. doi:10.1523/JNEUROSCI.2184-09.2009

Gandiga PC, Hummel FC, Cohen LG (2006) Transcranial DC stimulation (tDCS): a tool for double-blind sham-controlled clinical studies in brain stimulation. Clin Neurophysiol. doi:10.1016/j. clinph.2005.12.003

George MS, Nahas Z, Molloy M, Speer AM, Oliver NC, Li X-B, Ballenger JC (2000) A controlled trial of daily left prefrontal cortex TMS for treating depression. Biol Psychiatry. doi:10.1016/ S0006-3223(00)01048-9

Gironell A, Kulisevsky J, Lorenzo J, Barbanoj M, Pascual-Sedano B, Otermin P (2002) Transcranial magnetic stimulation of the cerebellum in essential tremor: a controlled study. Arch Neurol 59(August):413-417

Gironell A, Martínez-Horta S, Aguilar S, Torres V, Pagonabarraga J, Pascual-Sedano B, Ribosa-Nogué R (2014) Transcranial direct current stimulation of the cerebellum in essential tremor: a controlled study. Brain Stimul 7(3):491-492. doi:10.1016/j. brs.2014.02.001

Gluckman BJ, Neel EJ, Netoff TI, Ditto WL, Spano ML, Schiff SJ (1996) Electric field suppression of epileptiform activity in hippocampal slices. J Neurophysiol 76(6):4202-4205. http:// www.ncbi.nlm.nih.gov/pubmed/8985916. Accessed 16 Dec 2016

Golanov EV, Christensen JR, Reis DJ (2000) The medullary cerebrovascular vasodilator area mediates cerebrovascular vasodilation and electroencephalogram synchronization elicited from cerebellar fastigial nucleus in Sprague-Dawley rats. Neurosci Lett. doi:10.1016/S0304-3940(00)01228-3

Greicius MD, Flores BH, Menon V, Glover GH, Solvason HB, Kenna $\mathrm{H}$, Schatzberg AF (2007) Resting-state functional connectivity in major depression: abnormally increased contributions from subgenual cingulate cortex and thalamus. Biol Psychiat 62(5):429-437. doi:10.1016/j.biopsych.2006.09.020

Grimaldi G, Argyropoulos GP, Bastian A, Cortes M, Davis NJ, Edwards DJ, Celnik P (2016) Cerebellar transcranial direct current stimulation (ctDCS): a novel approach to understanding cerebellar function in health and disease. Neurosci Rev J Bring Neurobiol Neurol Psychiatry. doi:10.1177/1073858414559409

Haines DE, Dietrichs E, Sowa TE (1984) Hypothalamo-cerebellar and cerebello-hypothalamic pathways: a review and hypothesis concerning cerebellar circuits which may influence autonomic centers and affective behavior (part 2 of 2). Brain Behav Evol 24(4):210-220. doi:10.1159/000315995

Hansen ÅM, Garde AH, Skovgaard LT, Christensen JM (2001) Seasonal and biological variation of urinary epinephrine, norepinephrine, and cortisol in healthy women. Clin Chim Acta 309(1):25-35. doi:10.1016/S0009-8981(01)00493-4

Hansen ÅM, Garde AH, Persson R (2008) Sources of biological and methodological variation in salivary cortisol and their impact on measurement among healthy adults: a review. Scand J Clin Lab Invest 68(6):448-458. doi:10.1080/00365510701819127

Hashimoto M, Ohtsuka K, Ohtsuka K (1995) Transcranial magnetic stimulation over the posterior cerebellum during visually guided saccades in man. Brain 118:1185-1193

Herculano-Houzel S (2009) The human brain in numbers: a linearly scaled-up primate brain. Front Hum Neurosci 3:31. doi:10.3389/neuro.09.031.2009

Ho K-A, Bai S, Martin D, Alonzo A, Dokos S, Puras P, Loo CK (2014) A pilot study of alternative transcranial direct current stimulation electrode montages for the treatment of major depression. J Affect Disord 167:251-258. doi:10.1016/j. jad.2014.06.022
Hoaglin DC, Iglewicz B, Tukey JW (1986) Performance of some resistant rules for outlier labeling. J Am Statist Assoc 81(396):991999. doi:10.1080/01621459.1986.10478363

Holsheimer J, Nguyen J-P, Lefaucheur J-P, Manola L (2007) Cathodal, anodal or bifocal stimulation of the motor cortex in the management of chronic pain? Acta Neurochirurgica Suppl 97(Pt 2):5766. http://www.ncbi.nlm.nih.gov/pubmed/17691290. Accessed 31 May 2017

Holtzheimer PE, Mayberg HS (2012) Neuromodulation for treatmentresistant depression. F1000 Med Rep 4:22. doi:10.3410/M4-22

Holzschneider K, Mulert C (2011) Neuroimaging in anxiety disorders. Dial Clin Neurosci 13(4):453-61. http://www.ncbi.nlm.nih.gov/ pubmed/22275850. Accessed 29 Jun 2016

Hone-Blanchet A, Salas RE, Celnik P, Kalloo A, Schar M, Puts NAJ, Edden RA (2015) Co-registration of magnetic resonance spectroscopy and transcranial magnetic stimulation. J Neurosci Methods 242:52-57. doi:10.1016/j.jneumeth.2014.12.018

$\mathrm{Hu}$ D, Shen H, Zhou Z (2008) Functional asymmetry in the cerebellum: a brief review. Cerebellum 7(3):304-313. doi:10.1007/ s12311-008-0031-2

Jayaram G, Tang B, Pallegadda R, Vasudevan EVL, Celnik P, Bastian A, Suzuki J (2012) Modulating locomotor adaptation with cerebellar stimulation. J Neurophysiol 107(11):2950-2957. doi:10.1152/jn.00645.2011

Kabakov AY, Muller PA, Pascual-Leone A, Jensen FE, Rotenberg A (2012) Contribution of axonal orientation to pathway-dependent modulation of excitatory transmission by direct current stimulation in isolated rat hippocampus. J Neurophysiol 107(7):18811889. doi:10.1152/jn.00715.2011

Kalu UG, Sexton CE, Loo CK, Ebmeier KP (2012) Transcranial direct current stimulation in the treatment of major depression: a meta-analysis. Psychol Med 42(9):1791-1800. doi:10.1017/ S0033291711003059

Kennedy S, Evans K, Stephaniekrüger Helens, Mayberg FRCP, Meyer J, Vaccarino (2001) Changes in regional brain glucose metabolism measured with positron emission tomography after paroxetine treatment of major depression. Am J Psychiatry. doi:10.1176/appi.ajp.158.6.899

Kessler SK, Turkeltaub PE, Benson JG, Hamilton RH (2012) Differences in the experience of active and sham transcranial direct current stimulation. Brain Stimul 5(2):155-162. doi:10.1016/j. brs.2011.02.007

Konarski JZ, McIntyre RS, Grupp LA, Kennedy SH (2005) Is the cerebellum relevant in the circuitry of neuropsychiatric disorders? J Psychiatry Neurosci 30(3):178-187

Lacerda AL, Keshavan MS, Hardan AY, Yorbik O, Brambilla P, Sassi RB, Soares JC (2004) Anatomic evaluation of the orbitofrontal cortex in major depressive disorder. Biol Psychiat 55(4):353358. doi:10.1016/j.biopsych.2003.08.021

Lam RW, Levitan RD (2000) Pathophysiology of seasonal affective disorder: a review. J Psychiatry Neurosci JPN 25(5):469-80. http://www.ncbi.nlm.nih.gov/pubmed/11109298. Accessed 31 Aug 2017

Lee KA, Hicks G, Nino-Murcia G (1991) Validity and reliability of a scale to assess fatigue. Psychiatry Res 36(3):291-298. doi:10.1016/0165-1781(91)90027-M

Lefaucheur J-P, Antal A, Ayache SS, Benninger DH, Brunelin J, Cogiamanian F, Gerwig M (2017) Evidence-based guidelines on the therapeutic use of transcranial direct current stimulation (tDCS). Clin Neurophysiol 128(1):56-92. doi:10.1016/j. clinph.2016.10.087

Loo CK, Mitchell PB (2005) A review of the efficacy of transcranial magnetic stimulation (TMS) treatment for depression, and current and future strategies to optimize efficacy. J Affect Disord 88(3):255-267. doi:10.1016/j.jad.2005.08.001 
Loo CK, Sachdev P, Martin D, Pigot M, Alonzo A, Malhi GS, Mitchell P (2010) A double-blind, sham-controlled trial of transcranial direct current stimulation for the treatment of depression. Int J Neuropsychopharmacol 13(1):61. doi:10.1017/ S1461145709990411

Loo CK, Alonzo A, Martin D, Mitchell PB, Galvez V, Sachdev P, Pascual-Leone A (2012) Transcranial direct current stimulation for depression: 3-week, randomised, sham-controlled trial. Br J Psychiatry J Mental Sci 200(1):52-59. doi:10.1192/bjp. bp.111.097634

Lorr M, McNair DM, Fisher S (1982) Evidence for bipolar mood states. J Pers Assess 46(4):432-436. doi:10.1207/s15327752jpa4604_16

Martinot M-LP, Martinot J-L, Ringuenet D, Galinowski A, Gallarda T, Bellivier F, Artiges E (2011) Baseline brain metabolism in resistant depression and response to transcranial magnetic stimulation. Neuropsychopharmacology 36(13):2710-2719. doi:10.1038/ npp. 2011.161

Mayberg HS (2009) Targeted electrode-based modulation of neural circuits for depression. J Clin Investig 119(4):717-725. doi:10.1172/JCI38454

Mayberg HS, Brannan SK, Mahurin RK, Jerabek PA, Brickman JS, Tekell JL, Fox PT (1997) Cingulate function in depression: a potential predictor of treatment response. Neuroreport 8(4):1057-1061. http://www.ncbi.nlm.nih.gov/pubmed/9141092. Accessed 08 May 2017

McNair DM, Lorr M, Droppleman LF (1971) Manual for the profile of mood states. Eductional and Indutrial Testing Service, San diego

Merzagora AC, Foffani G, Panyavin I, Mordillo-Mateos L, Aguilar J, Onaral B, Oliviero A (2010) Prefrontal hemodynamic changes produced by anodal direct current stimulation. NeuroImage 49(3):2304-2310. doi:10.1016/j.neuroimage.2009.10.044

Middleton FA, Strick PL (2001) Cerebellar projections to the prefrontal cortex of the primate. J Neurosci 21(2):700-712. http://www. ncbi.nlm.nih.gov/pubmed/11160449. Accessed 04 Aug 2016

Minichino A, Bersani FS, Spagnoli F, Corrado A, De Michele F, Calò WK, Delle Chiaie R (2014) Prefronto-cerebellar transcranial direct current stimulation improves sleep quality in euthymic bipolar patients: a brief report. Behav Neurol 2014:1-3. doi:10.1155/2014/876521

Miranda PC, Lomarev M, Hallett M (2006) Modeling the current distribution during transcranial direct current stimulation. Clin Neurophysiol 117(7):1623-1629. doi:10.1016/j.clinph.2006.04.009

Miranda PC, Faria P, Hallett M (2009) What does the ratio of injected current to electrode area tell us about current density in the brain during tDCS? Clin Neurophysiol 120(6):1183-1187. doi:10.1016/j.clinph.2009.03.023

Miura M, Reis DJ (1969) Cerebellum: a pressor response elicited from the fastigial nucleus and its efferent pathway in brainstem. Brain Res. doi:10.1016/0006-8993(69)90269-8

Monte-Silva K, Kuo M-F, Hessenthaler S, Fresnoza S, Liebetanz D, Paulus W, Nitsche MA (2013) Induction of late LTP-like plasticity in the human motor cortex by repeated non-invasive brain stimulation. Brain Stimulat 6(3):424-432. doi:10.1016/j. brs.2012.04.011

Motohashi N, Yamaguchi M, Fujii T, Kitahara Y (2013) Mood and cognitive function following repeated transcranial direct current stimulation in healthy volunteers: a preliminary report. Neurosci Res 77(1-2):64-69. doi:10.1016/j.neures.2013.06.001

Nitsche MA, Paulus W (2001) Sustained excitability elevations induced by transcranial DC motor cortex stimulation in humans. Neurology 57(10):1899-1901. doi:10.1212/WNL.57.10.1899

Nitsche MA, Boggio PS, Fregni F, Pascual-Leone A (2009) Treatment of depression with transcranial direct current stimulation (tDCS): a review. Exp Neurol 219(1):14-19. doi:10.1016/j. expneurol.2009.03.038
Nitsche MA, Koschack J, Pohlers H, Hullemann S, Paulus W, Happe S (2012) Effects of frontal transcranial direct current stimulation on emotional state and processing in healthy humans. Front Psychiatry 3:58. doi:10.3389/fpsyt.2012.00058

O'Connell NE, Cossar J, Marston L, Wand BM, Bunce D, Moseley GL, de Souza LH (2012) Rethinking clinical trials of transcranial direct current stimulation: participant and assessor blinding is inadequate at intensities of $2 \mathrm{~mA}$. PLoS One. doi:10.1371/ journal.pone. 0047514

O'Halloran PD, Murphy GC, Webster KE (2004) Reliability of the bipolar form of the profile of mood states using an alternative test protocol. Psychol Rep 95(2):459-463. doi:10.2466/ pr0.95.2.459-463

Osuch EA, Ketter TA, Kimbrell TA, George MS, Benson BE, Willis MW, Post RM (2000) Regional cerebral metabolism associated with anxiety symptoms in affective disorder patients. Biol Psychiatry 48(10):1020-1023. http://www.ncbi.nlm.nih.gov/pubmed/11082477. Accessed 08 May 2017

Palm U, Schiller C, Fintescu Z, Obermeier M, Keeser D, Reisinger E, Padberg F (2012) Transcranial direct current stimulation in treatment resistant depression: a randomized double-blind, placebo-controlled study. Brain Stimul 5(3):242-251. doi:10.1016/j. brs.2011.08.005

Peña-Gómez C, Dídacidal-Piñeiro D, Clemente I, Bartrés-Faz D (2011) Down-regulation of negative emotional processing by transcranial direct current stimulation: effects of personality characteristics. PLoS One. doi:10.1371/journal.pone.0022812

Peng J, Liu J, Nie B, Li Y, Shan B, Wang G, Li K (2011) Cerebral and cerebellar gray matter reduction in first-episode patients with major depressive disorder: a voxel-based morphometry study. Eur J Radiol 80(2):395-399. doi:10.1016/j.ejrad.2010.04.006

Perciavalle V, Apps R, Bracha V, Delgado-García JM, Gibson AR, Leggio M, Sánchez-Campusano R (2013) Consensus paper: current views on the role of cerebellar interpositus nucleus in movement control and emotion. Cerebellum 12(5):738-757. doi:10.1007/ s12311-013-0464-0

Persson R, Garde AH, Hansen ÅM, Österberg K, Larsson B, Ørbæk P, Karlson B (2008) Seasonal variation in human salivary cortisol concentration. Chronobiol Int 25(6):923-937. doi:10.1080/07420520802553648

Plazier M, Joos K, Vanneste S, Ost J, De Ridder D (2012) Bifrontal and bioccipital transcranial direct current stimulation (tDCS) does not induce mood changes in healthy volunteers: a placebo controlled study. Brain Stimul. doi:10.1016/j.brs.2011.07.005

Popa T, Russo M, Vidailhet M, Roze E, Lehéricy S, Bonnet C, Gallea C (2013) Cerebellar rTMS stimulation may induce prolonged clinical benefits in essential tremor, and subjacent changes in functional connectivity: an open label trial. Brain Stimul 6(2):175-179. doi:10.1016/j.brs.2012.04.009

Pope PA, Miall RC (2012) Task-specific facilitation of cognition by cathodal transcranial direct current stimulation of the cerebellum. Brain Stimul 5(2):84-94. doi:10.1016/j.brs.2012.03.006

random.org (2017) Sequence generator. https://www.random.org/ sequences/. Accessed 2 Feb 2017

Remue J, Baeken C, De Raedt R (2016) Does a single neurostimulation session really affect mood in healthy individuals? A systematic review. Neuropsychologia 85:184-198. doi:10.1016/j. neuropsychologia.2016.03.012

Sadleir RJ, Vannorsdall TD, Schretlen DJ, Gordon B, Pruitt JC (2010) Transcranial direct current stimulation (tDCS) in a realistic head model. NeuroImage. doi:10.1016/j.neuroimage.2010.03.052

Saturnino GB, Antunes A, Thielscher A (2015) On the importance of electrode parameters for shaping electric field patterns generated by tDCS. NeuroImage 120:25-35. doi:10.1016/j. neuroimage.2015.06.067 
Schmahmann JD (2004) Disorders of the cerebellum: ataxia, dysmetria of thought, and the cerebellar cognitive affective syndrome. J Neuropsychiatry Clin Neurosci 16(3):367-378. doi:10.1176/ jnp.16.3.367

Schutter DJLG, van Honk J (2005) The cerebellum on the rise in human emotion. Cereb (Lond, Engl) 4(4):290-294. doi:10.1080/14734220500348584

Schutter DJLG, van Honk J (2009) The cerebellum in emotion regulation: a repetitive transcranial magnetic stimulation study. Cerebellum 8(1):28-34. doi:10.1007/s12311-008-0056-6

Schutter DJL, van Honk J, d'Alfonso AA, Peper JS, Panksepp J (2003) High frequency repetitive transcranial magnetic over the medial cerebellum induces a shift in the prefrontal electroencephalography gamma spectrum: a pilot study in humans. Neurosci Lett. doi:10.1016/S0304-3940(02)01077-7

Seminowicz DA, Mayberg HS, McIntosh AR, Goldapple K, Kennedy S, Segal Z, Rafi-Tari S (2004) Limbic-frontal circuitry in major depression: a path modeling metanalysis. NeuroImage 22(1):409-418. doi:10.1016/j.neuroimage.2004.01.015

Shacham S (1983) A shortened version of the profile of mood states. J Pers Assess 47(3):305-306. doi:10.1207/s15327752jpa4703_14

Shah B, Nguyen TT, Madhavan S (2013) Polarity independent effects of cerebellar tDCS on short term ankle visuomotor learning. Brain Stimul. doi:10.1016/j.brs.2013.04.008

Shahid S, Wen P, Ahfock T (2013) Numerical investigation of white matter anisotropic conductivity in defining current distribution under tDCS. Comput Methods Programs Biomed 109(1):48-64. doi:10.1016/j.cmpb.2012.09.001

Snider RS, Maiti A (1976) Cerebellar contributions to the papez circuit. J Neurosci Res 2(2):133-146. doi:10.1002/jnr.490020204

Stoodley CJ (2012) The cerebellum and cognition: evidence from functional imaging studies. Cereb (Lond, Engl) 11(2):352-365. doi:10.1007/s12311-011-0260-7

Stoodley CJ, Schmahmann JD (2010) Evidence for topographic organization in the cerebellum of motor control versus cognitive and affective processing. Cortex 46(7):831-844. doi:10.1016/j. cortex.2009.11.008

Strata P (2015) The emotional cerebellum. Cereb (Lond, Engl) 14(5):570-577. doi:10.1007/s12311-015-0649-9

Tadini L, El-Nazer R, Brunoni AR, Williams J, Carvas M, Boggio P, Fregni F (2011) Cognitive, mood, and electroencephalographic effects of noninvasive cortical stimulation with weak electrical currents. J ECT 27(2):134-140. doi:10.1097/ YCT.0b013e3181e631a8

Taylor WD, MacFall JR, Payne ME, McQuoid DR, Provenzale JM, Steffens DC, Krishnan KRR (2004) Late-life depression and microstructural abnormalities in dorsolateral prefrontal cortex white matter. Am J Psychiatry 161(7):1293-1296. doi:10.1176/ appi.ajp.161.7.1293

Telzer EH, Mogg K, Bradley BP, Mai X, Ernst M, Pine DS, Monk CS (2008) Relationship between trait anxiety, prefrontal cortex, and attention bias to angry faces in children and adolescents. Biol Psychol 79(2):216-222. doi:10.1016/j.biopsycho.2008.05.004

Terry P, Lane A, Fogarty G (2003) Construct validity of the profile of mood states - adolescents for use with adults. Psychol Sport Exerc 4(2):125-139. doi:10.1016/S1469-0292(01)00035-8

Tortella G, Casati R, Aparicio LVM, Mantovani A, Senço N, D’Urso G, Brunoni AR (2015) Transcranial direct current stimulation in psychiatric disorders. World J Psychiatry 5(1):88-102. doi:10.5498/wjp.v5.i1.88

Tukey JW (1977) Exploratory data analysis. Addison-Wesley. http:// cds.cern.ch/record/107005. Accessed 06 July 2017

Turner BM, Paradiso S, Marvel CL, Pierson R, Boles Ponto LL, Hichwa RD, Robinson RG (2007) The cerebellum and emotional experience. Neuropsychologia 45(6):1331-1341. doi:10.1016/j. neuropsychologia.2006.09.023

Vanderhasselt M-A, De Raedt R, Brunoni AR, Campanhã C, Baeken C, Remue J, Zahn M (2013) tDCS over the left prefrontal cortex enhances cognitive control for positive affective stimuli. PLoS One 8(5):e62219. doi:10.1371/journal.pone.0062219

Wallace D, Cooper NR, Paulmann S, Fitzgerald PB, Russo R, Kim G, Fregni F (2016) Perceived comfort and blinding efficacy in randomised sham-controlled transcranial direct current stimulation (tDCS) trials at $2 \mathrm{~mA}$ in young and older healthy adults. PLoS One 11(2):e0149703. doi:10.1371/journal.pone.0149703

Wang D, Buckner RL, Liu H (2013) Cerebellar asymmetry and its relation to cerebral asymmetry estimated by intrinsic functional connectivity. J Neurophysiol 109(1):46-57. doi:10.1152/ jn.00598.2012

WHO (2016) Depression. WHO

Zunhammer M, Busch V, Griesbach F, Landgrebe M, Hajak G, Langguth B (2011) rTMS over the cerebellum modulates temperature detection and pain thresholds through peripheral mechanisms. Brain Stimul 4(4):210-217.e1. doi:10.1016/j.brs.2010.11.002 